\title{
No limiar do mundo: a posição de Heidegger sobre a diferença entre animais e humanos
}

\author{
FERnando Rodrigues \\ Mestre em Filosofia pela Universidade Federal do \\ Paraná - UFPR e doutorando em Filosofia no \\ Instituto de Filosofia e Ciências Humanas \\ da Universidade Estadual de Campinas \\ - IFCH/UNICAMP
}

Resumo: A posição de Heidegger quanto à diferença entre o animal e o homem é muitas vezes tomada por não científica ou conservadora. Essa é também a posição de Peter Sloterdijk em seu opúsculo Regras para o parque humano. Neste artigo, argumenta-se que um entendimento correto da posição de Heidegger sobre este tema depende da compreensão adequada dos conceitos de transcendência, mundo e formação de mundo, tais como explicitados em Ser e tempo (1927) e nos Conceitos fundamentais da metafísica (1929/30). Assim procedendo, mostra-se que a descrição oferecida por Sloterdijk em suas Regras tende a simplificar o complexo horizonte de problemas por onde Heidegger transita ao enunciar uma diferença radical entre o animal e o homem, mostrando-se assim como restrita do ponto de vista interpretativo.

Palavras-chave:Heidegger.Sloterdijk. Dasein. Animalidade. Mundo.
Abstract: Heidegger's position on the difference between man and animal is often taken as non-scientific or even conservative. This is also Peter Sloterdijk's view, as defended in his essay Regeln für den Menschenpark. In this paper we intend to show how a due understanding of Heidegger's statements depends on a proper understanding of the concepts of transcendence, world and world-forming, as explained in Being and Time (1927) and in his The Fundamental Concepts of Metaphysics (1929/30). By doing so, we may prove that the description offered by Sloterdijk in its Regeln tends to simplify the complex horizon of problems wherein Heidegger moves when he defends a radical difference between man and animal, and thus we intend to show how Sloterdijk's interpretation of Heidegger is in itself restricted.

Keywords: Heidegger. Sloterdijk. Dasein. Animality. World. 


\section{Introdução}

Depois que Charles Darwin (1809-1882) publicou A origem das espécies, em 1859, pode parecer temerário afirmar, na universidade e demais ambientes comprometidos com o saber e a ciência, que há uma diferença radical entre os animais e o homem. Em geral, tal posicionamento é considerado reacionário: tratar-se-ia ou bem de simples cegueira ou bem de algum tipo de dogmatismo de cunho filosófico ou religioso. Farta de evidências, a história natural da evolução das espécies e da subseqüente diversidade da vida na Terra instituiu uma visão revolucionária de mundo. Nela, a natureza do mundo é reinterpretada em diversas direções e algumas de suas proposições, como a assunção da comum ancestralidade de todos os viventes, faz reaproximar de modo peculiar o animal e o homem, superando antigos abismos e colocando-os lado a lado como parentes ora mais próximos ora mais distantes. Num contexto como este, um questionamento sobre a diferença básica entre os animais e o homem não passaria de mera reformulação do discurso humanista tradicional.

Poucos pensadores detiveram-se tão obstinadamente quanto Martin Heidegger (1889-1976) num questionamento sobre a diferença peculiaríssima dos humanos. Desde Ser e tempo (1927), Heidegger marca o caráter especial da reflexão filosófica sobre a essência do homem, o Dasein, o ente que compreende ser. ${ }^{1} \mathrm{Na}$ me-

1. Ainda que o objetivo de Ser e tempo não seja o de elaborar uma antropologia filosófica, seria temerário negar que a analítica existencial, momento decisivo da dupla tarefa a ser cumprida com vistas ao empreendimento da questão sobre o sentido do ser em geral, põe o homem em questão de um modo radical. Ademais, ainda que a questão do ser (Seinsfrage) de fato se configure como a mola propulsora e o fio condutor da vida de pensamento de Heidegger, há de se observar que tanto em Ser e tempo quanto em sua Carta sobre o humanismo (1946), por exemplo, publicada duas décadas depois da aparição do opus magnum, é o homem o ente por primeiro interpelado na reflexão que visa ao questionamento do ser. Em Ser e tempo, porque Dasein, o homem, é compreensão de ser. Na Carta, porque aquilo que se consuma na linguagem é o nexo de pertencimento do homem ao ser, isto é, o que se consuma no pensar da linguagem é a imbricação da verdade do ser e da essência do homem. A despeito da centralidade da questão do ser, neste trabalho nos interessa o problema da diferença peculiaríssima do homem. 
dida em que suas teses, entretanto, não pressupõem as de Darwin, senão que, de certo modo, colocam-nas em questão justamente no que concerne à sua sustentabilidade enquanto proposições fundamentais sobre a essência do homem, não é de estranhar que sua obra seja simplesmente tomada por não científica ou conservadora quanto às suas posições acerca da diferença entre o modo de ser de animais e humanos.

É assim que Peter Sloterdijk (1947-), por exemplo, compreende a posição de Heidegger. ${ }^{2}$ Em seu opúsculo Regras para o parque humano, texto de uma polêmica conferência pronunciada em julho de 1999 na cidade de Elmau, Sloterdijk tornou explícito o seu pathos anti-heideggeriano ao caricaturar o autor de Ser e tempo como um "anjo colérico com espada em riste", como se Heidegger não fizesse senão caminhar entre o animal e o homem com o fim de "impedir qualquer comunhão ontológica" entre eles. ${ }^{3}$ Entretanto, o fato de Heidegger abdicar resolutamente de um questionamento acerca da origem das espécies não é fator suficiente para tornálo um pensador reacionário ou um neo-humanista.

No presente texto, mostra-se que um entendimento correto do posicionamento de Heidegger acerca da diferença entre animais e homens depende da adequada compreensão de sua interpretação do fundamento do existir humano, a transcendência (Transzendenz). Veremos que a compreensão da posição de

2. Nascido em 1947, na cidade de Karlsruhe, Alemanha, Peter Sloterdijk ganhou projeção internacional com a publicação, em 1983, de sua Kritik der zynischen Vernunft (Crítica da razão cínica - ainda sem tradução para o português), um livro sobre o cinismo enquanto fenômeno social da história européia. Sloterdijk leciona filosofia e estética em Karlsruhe e em Viena e seu trabalho não se deixa rotular com facilidade. É costumeiramente descrito como um dos pensadores e ensaístas alemães mais instigantes e originais da atualidade. Na última década veio a público sua produção monumental, Esferas, descrita por ele próprio como sua obra mais fundamental. De inserção midiática, um filósofo das mídias, Peter Sloterdijk apresenta o programa de televisão "Das philosophische Quartet", no canal alemão ZDF, ao lado do também filósofo e escritor Rüdiger Safranski.

3. Sloterdijk, P. Regras para o parque humano: uma resposta à carta de Heidegger sobre o humanismo. Trad. de José Oscar de Almeida Marques. São Paulo: Estação Liberdade, 2000, p.25. 
Heidegger quanto à essência da transcendência é a condição para a correta apropriação de sua afirmação de que o homem, e somente ele, é formador de mundo. Dada a centralidade da noção de formação de mundo, clarifica-se brevemente aqui também o conceito de mundo (Welt) em Heidegger, tal como formulado no período de publicação de Ser e tempo. Este esclarecimento é pressuposto para a compreensão de sua afirmação de que o animal é pobre de mundo (Weltarmut). Percorrido este caminho, obtém-se a fixação conceitual do sentido adequado da proposição heideggeriana quanto à diferença entre animais e humanos, bem como fica claro que a descrição do problema tal como oferecida por Peter Sloterdijk em suas Regras é insuficiente para uma crítica interna dos posicionamentos de Heidegger, na medida em que se revela como restrita do ponto de vista interpretativo.

\section{O animal é pobre de mundo, o homem é formador de mundo}

Na preleção do semestre de inverno de 1929/30, Os conceitos fundamentais da metafísica: mundo - finitude - solidão, Heidegger defrontou-se diretamente com o problema de determinação da diferença entre o animal e o homem. Absolutamente avesso à tese tradicional, segundo a qual a racionalidade é a diferença específica do homem, Heidegger tampouco pode aceitar que esse questionamento se deixe pautar numa teoria da evolução das espécies, justamente por haver diagnosticado que toda teoria deste gênero já pressupõe determinações prévias tanto do que seja o homem como também do que seja o animal. A questão sobre se o homem descende ou não dos símios, por exemplo, já pressuporia uma diferença entre eles, ainda que não se proponha a pensá-la. Do mesmo modo, a afirmação de que essa diferença consiste na racionalidade não chega, para Heidegger, a questionar a essência da racionalidade. ${ }^{4}$

4. Para se compreender o que Heidegger tem em vista ao falar em essência (Wesen), é fundamental ter claro que seu pensamento opera uma superação radical da tradição essencialista. Essência, em Heidegger, nunca diz de um quê, de um quid (Was), mas refere-se ao como (Wie) do essenciar-se (acontecer, aparecer) de um ente, diz respeito ao traço peculiar do seu modo de ser 
Com sua investigação fenomenológico-hermenêutica, por seu turno, Heidegger visa a uma determinação da animalidade do animal, e quer empreender uma investigação cujo ponto de partida seja o próprio animal, e não o homem. Ou é assim, ou não se poderá dar expressão à diferença previamente determinante em toda distinção entre animalidade e humanidade. A promissória que Heidegger assinará aqui é a seguinte: a apreensão em caracteres ontológicos do que seja a animalidade depende de se poder enunciar o que perfaz a vitalidade do vivente em geral, em sua distinção ante o sem-vida, ante a pedra, por exemplo. Para Heidegger, a zoologia morfológica, mesmo que posteriormente acrescida de uma psicologia animal, não dispõe dos meios necessários para uma enunciação da essência da animalidade. $\mathrm{O}$ mais das vezes, ela sequer chega a perceber que a animalidade encerra vitalidade, ainda que a proposição "o animal vive" seja um de seus pressupostos. Donde o caráter mais originário, no que concerne à investigação do modo de ser do animal, da questão sobre o que seja a vida (Leben).

Mas qual o procedimento metodológico adequado com vistas à determinação do que seja a vida em geral? Qual o caminho a ser percorrido com vistas à fixação conceitual da vitalidade do vivente? Pois é pouco provável que possamos esperar que advenham dos animais relatos a seu próprio respeito, a respeito do seu modo de ser. Entretanto, ao menos para nós, enquanto intérpretes, o animal de alguma forma se mostra em seu modo de ser, concedendo uma ou outra informação sobre si, na medida em que se expressa por certos movimentos, sons ou ruídos.

(Seinsmodus). Como se lê no $§ 7$ de Ser e tempo, "apreender o ser dos entes e explicar o próprio ser é a tarefa da ontologia”. Ora, uma vez que a ontologia de Heidegger é fenomenológico-hermenêutica, os conceitos hauridos da tradição, de cuja análise ele por vezes se vale, precisam ser pensados numa tal base. "A expressão 'fenomenologia' significa, antes de tudo, um conceito de método. Não caracteriza a qüididade real dos objetos da investigação filosófica, o quê dos objetos, mas o seu como, o como dos objetos. [...] O conceito fenomenológico de fenômeno propõe, como o que se mostra, o ser dos entes, o seu sentido, suas modificações e derivados". Heidegger, M. Sein und Zeit. Achtzehnte Auflage. Tübingen: Max Niemeyer Verlag, 2001, p. 34-9. 
Uma exegese da vida animal parece dispor, de certo modo, de um ponto de partida. Valendo-se disso, Heidegger vai pressupor três teses, ou uma tese tripartite, a fim de poder aceder a uma caracterização da essência da vida: 1) a pedra é sem mundo; 2) o animal é pobre de mundo; 3) o homem é formador de mundo. ${ }^{5}$ Esta pressuposição, que pretende mobilizar um questionamento sobre a essência da animalidade ao tocar no problema da determinação da vida em sentido geral, há de permitir também uma confirmação de mundo como a estrutura fundamental e distintiva do homem, como o ente capaz de compreender e interpretar o ente como tal e no seu todo.

Com a tese "o animal é pobre de mundo", Heidegger tem em vista a apreensão da essência da animalidade enquanto tal, logo, a tese não diz respeito a este ou àquele animal em específico, mas à totalidade do gênero animal. Na medida em que pretende apreender pelo recurso ao método fenomenológico-hermenêutico o traço mais básico da animalidade, esta tese é pressuposição de toda zoologia. Porém, qual é o critério de medida e verdade de uma tese como essa, essencialmente ontológica, filosófica? Heidegger surpreende: ainda que tal proposição não provenha da zoologia, ela tampouco pode ser legitimamente discutida sem um recurso atencioso às pesquisas empíricas desta ciência. Não nos deparamos, então, com uma ambigüidade? De fato. Mas Heidegger tem claro, neste momento de sua reflexão filosófica, que a relação entre metafísica e ciência positiva ainda precisaria ser pensada em sua ambigüidade característica. Caberia, inclusive, uma delimitação mais distinta da relação da filosofia, do questionamento filosófico,

5. Faz parte das regras do jogo fenomenológico-hermenêutico que teses possam ser pressupostas, a fim de que a sua comprovação seja averiguada no próprio decurso e empreendimento da investigação. Este, aliás, é o sentido básico do círculo da compreensão, também chamado círculo hermenêutico, cuja apresentação se dá no $\$ 32$ de Ser e tempo. O compreender é sempre um ter prévio (Vorhabe), uma visão prévia (Vorsicht), uma concepção prévia (Vorgriff). A tarefa hermenêutica básica consiste justamente em poder submeter tudo o que se sabe como prévio (vor) a um exame e revisão detidos, seja com vistas à sua confirmação ou à sua denegação. 
com a zoologia e, do mesmo modo, com a biologia, entendida como ciência do vivente em geral.

Mas antes de proceder a qualquer conclusão, é urgente clarificar aqui o sentido da expressão pobreza de mundo, a fim de que se tenha claro que ela não faz senão apontar para uma diferenciação modal, para a especificidade de um modo de ser, e não tem nada que ver com um juízo valorativo de caráter depreciativo. Pobre de mundo quer dizer: o animal tem e não tem mundo. Heidegger insiste reiteradamente que a noção de pobreza não diz de um menos em relação à riqueza de outro ente, ou do baixo com relação a um alto. Para o autor, permanece altamente problemático o falatório acerca de um caráter mais elevado do homem em relação aos animais. Razão pela qual o seu esforço, com as três teses interpretativas, é tão-somente o de poder descrever, pelo recurso ao método fenomenológico-hermenêutico, as diferenças modais que se explicitam nos distintos modos de ser nelas considerados, o ser-pedra, o ser-animal e o ser-homem.

Vê-se, com isso, que o conceito de pobreza tem uma significação muito específica, cuja compreensão depende do esclarecimento do modo de estar imbricado com o mundo que é próprio ao animal: ter e não ter. A tese de Heidegger é a seguinte: ser pobre significa ser privado. E este ser-privado tem o sentido, no caso dos animais, de um serprivado de acesso ao ente no seu como. A pedra, diferentemente do animal, é de tal modo que sequer pode ser ou não ser privada de acesso: a pedra é sem mundo, e isso é expressão de uma total ausência de acessibilidade. Como pura pedra, ela pertence ao contexto da natureza física material e de suas leis. $\mathrm{O}$ animal, ao contrário, na especificidade de seu modo de ser, estabelece determinados vínculos com o seu círculo envoltório (Umring), com o seu alimento e com sua presa, com seus inimigos e predadores, com seus parceiros sexuais etc. Mas isso não implica dizer que o animal os compreenda como algo, como entes, como sendo isso ou aquilo, dessa ou daquela maneira.

Permanece essencial, porém, determinar o isso a que o animal acha-se ligado. Do mesmo modo, o questionamento filosófico precisa apreender o sentido, na vida animal, da sua ligação com 
um entorno. De modo mais direto: é necessário ter clareza sobre a característica peculiar do ambiente dentro do qual o animal desempenha suas aptidões. Para Heidegger, é inegável que a animalidade e a vida em geral são marcadas pelo acesso (Zugang) a isso em meio a que o ser-vivo se acha. Sua interpretação se desenvolve no seguinte sentido: o animal conecta-se com o seu entorno e tem assim o seu ambiente (Umgebung; Umring). Durante a sua vida, no entanto, o animal encerra-se aí, em seu mundo-ambiente, como um mundo que não se estreita nem se amplia. Naturalmente, há sempre a possibilidade da fuga ou do rapto, ou do simples ser retirado de seu ambiente, mas isso sempre implica menos-vida ou não-mais-vida, isto é, morte.

É por considerar esta restrição ou aprisionamento do animal a um círculo envoltório delimitado que Heidegger enuncia a proposição: $o$ animal tem e não tem mundo. Esta tese, para além da contradição lógica a que dá expressão, aponta para dois extremos: ausência de mundo e formação de mundo. Na preleção do semestre de inverno de 1929/30, ela serve como o fio condutor capaz de conduzir à compreensão do fenômeno do mundo: a abertura (Offenbarkeit) do ente como ente no seu todo. ${ }^{6}$ Além disso, o que

6. É preciso observar que a palavra portuguesa "abertura", aqui empregada para a alemã Offenbarkeit, não traduz todos os aspectos do fenômeno designado pelo termo original, permanecendo deficitária. A simples tradução por "abertura" oblitera o aspecto de possibilidade próprio dos adjetivos alemães terminados em -bar, tais como erkennbar, manipulierbar, verwechselbar e o próprio offenbar - além de inúmeros outros - de onde advém, por derivação, o substantivo Offenbarkeit. Boa tradução para este termo talvez fosse um dos seguintes neologismos: aberturidade, abertureidade ou aberturabilidade, os quais, entretanto, por si só contribuiriam pouco para a elucidação do fenômeno em questão. Também não nos parece que manifestidade, tal como sugere a tradução para o inglês de W. McNeill e N. Walker de Offenbarkeit por manifestness, esteja livre de complicações - ainda que na fala alemã cotidiana, de fato, o adjetivo offenbar designe aquilo que está manifesto, no sentido do que é por si mesmo claro, evidente ou óbvio (cf. Wabrig Deutsches Wörterbuch) -, por conta de seu comprometimento com as tradições teológica e gnosiológica. Mas há ainda um outro complicador: o leitor da única tradução de Ser e tempo disponível em língua portuguesa, publicada pela brasileira Editora Vozes, tende a associar "abertura" à expressão alemã Erschlossenheit (esp. Aperturidad; ing. Disclosedness; fr. Ouverture), termo 
ela diz é de significação essencial: o animal, em seu modo de ser, é determinado pelo fato de dispor de acessibilidade a... Este é um traço que o animal, aliás, compartilha com o homem, a acessibilidade (Zugänglichkeit), entendida como a capacidade - do animal e do homem - de ter acesso a algo. Toda a diferença entre o animal e o homem, porém, repousa numa distinção fundamental entre os modos de acessibilidade a algo que lhes são característicos.

O animal é caracterizado por um ser-aberto, por ser-aberto no seu interagir [Benehmen] com isso que chamamos de círculo envoltório. $\mathrm{O}$ animal carece da capacidade de apreender como um ente aquilo para que ele está aberto. Todavia, [...] ao homem pertence um ser-aberto para... que se configura de tal modo que este ser-aberto para... tem o caráter do apreender algo como algo. A este modo de ligar-se ao ente denominamos comportamento [Verbalten], distinguindo-o do interagir dos animais.

Vê-se que nesta preleção de 1929/30 acessibilidade é algo que caracteriza também o modo de ser do animal. Nos domínios do círculo envoltório que o circunda, o animal desfruta de um tipo de acessibilidade que se entende sob os termos do ter e não ter mundo. Seu modo de ser, entretanto, é a catividade ou o estar-absorvido (Benommenheit). Vitalidade, animalidade descrevem, assim, um ser-impelido-em-direção-a... cujo caráter é, de certo modo, o de um lançar-se para fora de si. Mas neste lançamento, entretanto - ao

empregado em Ser e tempo para designar a constituição básica do aí $(D a)$ do Dasein, a própria clareira (Lichtung), e que, do mesmo modo, ainda que por razões diversas, bem se poderia traduzir pelos neologismos propostos nesta nota. Agora, tanto Offenbarkeit quanto Erschlossenheit vêm à tona, em seus contextos específicos, numa vinculação essencial com o conceito de mundo $($ Welt $)$, conceito chave na reflexão de Heidegger no período que vai de Ser e tempo aos Conceitos Fundamentais. É desta vinculação que nos valemos aqui para traduzir, um tanto indistintamente, ambos os termos por abertu$r a$, recorrendo ainda às formulações dos tradutores brasileiros. Este recurso, entretanto, não deve nos desobrigar da investigação específica dos motivos subjacentes à modificação terminológica operada por Heidegger, pesquisa com a qual, por ora, necessitaremos permanecer em débito.

7. Heidegger, M. Die Grundbegriffe der Metaphysik: Welt - Endlichkeit Einsamkeit. In: Gesamtausgabe. Band 29/30. Frankfurt-am-Main: Vittorio Klostermann, Zweite Auflage, 1992, p. 443. 
ouvir ou ao capturar sua presa, por exemplo - o animal não faz senão desempenhar uma aptidão (Fähigkeit), de tal modo que o seu estar-ligado com o que se dá ao seu entorno é um estar-absorvido por um circulo de desinibiçôes (Enthemmungskreis).

Assim, não se dá para o animal uma abertura do ente como ente, do sendo enquanto sendo. O ente, ao contrário, é que o retém absorvido e o cativa numa tal absorção, e isso possibilita o seu modo de ser como um interagir (Benebmen), um desempenho de aptidões (Benehmung): "a vida não é nada além da luta do animal com o seu círculo. Através desta luta ele é absorvido, sem jamais estar junto a si mesmo em sentido próprio". ${ }^{8}$ No Dasein humano, porém, toda acessibilidade se funda numa abertura do ente como tal e num todo, isto é, todo comportamento (Verbalten) face ao ente se funda na abertura de mundo que caracteriza essencialmente o homem, donde a tese: o homem é formador de mundo. Pelo exposto, extrai-se que a compreensão de Heidegger sobre o que seja propriamente comportamento (Verhalten) é bastante singular, uma vez que dela depende o entendimento da diferença básica entre animais e humanos. Além disso, o comportamento se dá sempre como um comportar-se com o ente como ente na totalidade. Donde a necessidade de que, no que segue, esta definição de comportamento seja elucidada.

\section{Transcendência, mundo e comportamento humano}

Logo no $\$ 1$ de Ser e tempo, observou Heidegger: "Todo mundo compreende: 'o céu é azul', 'eu sou feliz' e coisas semelhantes. Esta compreensibilidade comum, entretanto, não faz senão demonstrar uma incompreensibilidade. Ela torna manifesto que em cada comportar-se e ser com o ente enquanto ente um enigma subjaz já sempre a priori". Embora sucinta, esta sentença torna explícito que, para Heidegger, o modo de ser mais básico do ser humano consiste num ser-aberto para a possibilidade de ser e comportar-se com o ente enquanto

8. Idem, p. 374.

9. Heidegger, M. Sein und Zeit. Achtzehnte Auflage. Tübingen: Max Niemeyer Verlag, 2001, p. 4, grifo meu. 
ente. Assim, a própria analítica existencial, cujo empreendimento é apresentado na introdução de Ser e tempo como exigência de uma investigação sobre o sentido do ser em geral, envolve e mobiliza de saída um questionamento sobre o problema básico da condição de possibilidade do comportamento humano em sentido geral, isto é, do comportamento que é possível, para o Dasein humano, travar consigo mesmo, com o outro e com o ente que é distinto de si.

Ora, uma das teses básicas que perpassam Ser e tempo é a de que toda tematização deste enigma sempre inserido a priori em cada comportamento do Dasein com os entes não é nada senão uma investigação sobre a essência da abertura de mundo que se consuma com a transcendência da existência. ${ }^{10}$ Deste modo, o conceito fenomenológico-hermenêutico de mundo elaborado por Heidegger no período de Ser e tempo visa justamente a dar expressão ao fenômeno a partir do qual o comportamento humano se faz possível. Em Ser e tempo, é o vigor do fenômeno do mundo o que explicita a condição de possibilidade do comportamento humano e da descoberta do ente como ente ${ }^{11}$. Mundo, por sua vez, entendido como instância de conformatividade (Berwandtnis) e significatividade (Bedeutsamkeit), é o horizonte ou o na-direção-de-quê (Woraufbin) da transcendência, ou, em terminologia propriamente

10. Não por acaso, o conceito de abertura (Erschlossenheit) em Ser e tempo remete sempre a uma abertura de mundo: "a descoberta do ente intramundano funda-se na abertura de mundo". Heidegger, M., Sein und Zeit, p. 220. Não por outra razão é que "o compreender pode colocar-se primariamente na abertura de mundo, ou seja, o Dasein pode, numa primeira aproximação e na maior parte das vezes, compreender-se a partir de seu mundo". Idem, p. 146. Pois "enquanto abertura do ai $(D a)$, o compreender sempre diz respeito a todo o ser-no-mundo. Em todo compreender de mundo, a existência está compreendida e vice-versa". Idem, p. 152. E ainda mais: "com o ser do Dasein, o mundo já se abriu de modo essencial; com a abertura de mundo, já se descobriu o "mundo". Idem, p. 203.

11. Em minha dissertação de mestrado propus-me explicitar o modo como o conceito fenomenológico-hermenêutico de mundo elaborado no período de Ser e tempo dá expressão ao fenômeno a partir e por meio do qual irrompe a possibilidade do comportamento humano ou, em termos da tradição, da descoberta do ente. O texto acha-se disponível no seguinte endereço eletrônico: http://www.filosofia.ufpr.br/docs/diss_fernando_rodrigues2007.pdf 
heideggeriana e aqui ainda carente de elucidação, é o signo do ultrapassamento do ente, do vigor da diferença entre ser e ente, a diferença ontológica.

Compreender a peculiaridade da noção heideggeriana de mundo é condição para uma apropriação adequada de sua tese sobre a diferença entre animais e humanos. $\mathrm{O}$ que argumentamos aqui, de modo a encaminhar nossa avaliação da posição de Sloterdijk, é que este conceito de mundo, por sua vez, somente se deixa elucidar de modo preciso enquanto referido ao acontecimento da transcendência, o ultrapassamento do ente. Para Heidegger, transcendência é a constituição primordial do Dasein, do ente que, na medida em que existe, é já ele mesmo um ultrapassar, uma ultrapassagem. ${ }^{12}$ Transcendência não é um comportamento do sujeito, nem tampouco diz intencionalidade, mas é, antes, a condição de possibilidade de toda e qualquer modalidade de comportamento do ser humano, seja consigo mesmo, seja com os entes distintos de si.

Aquilo que o Dasein ultrapassa na transcendência não é uma brecha ou uma fronteira "entre" ele mesmo e os objetos. Os entes, ao contrário, entre os quais o Dasein também está facticamente, é que são ultrapassados pelo Dasein. Os objetos são previamente ultrapassados; mais exatamente, os entes são ultrapassados e podem, então, tornar-se objetos. O Dasein é lançado, fáctico, completamente em meio à natureza por meio de sua corporeidade, e transcendência consiste no fato de que os entes, entre os quais o Dasein está e aos quais ele pertence, são ultrapassados pelo Dasein. Em outras palavras, enquanto transcendência, o Dasein está além da natureza, muito embora, enquanto fáctico, ele permaneça envolto pela natureza. Transcendendo, isto é, enquanto livre, o Dasein é estranho à natureza. ${ }^{13}$

12. Cf. Heidegger, M. Metaphysiche Anfangsgründe der Logik im Ausgang von Leibniz. In: _. Gesamtausgabe. Band 26. 2., durchgesehene Auflage. Frankfurt-am-Main: Vittorio Klostermann, 1990, p. 210. Cf. também Heidegger, M. Vom Wesen des Grundes. In: ___. A essência do fundamento. Edição bilíngüe. Lisboa: Edições 70, 1988, p. 32.

13. Heidegger, M. Metaphysiche Anfangsgründe der Logik im Ausgang von Leibniz. In: Gesamtausgabe. Band 26. 2., 212. E importante ressaltar 
Com a transcendência da existência, o próprio ente é o ultrapassado, e isso numa totalidade. O ultrapassado, o ente mesmo, desvenda-se, descobre-se, e aí pode vigorar mundo. A transcendência, assim, dá-se na direção de mundo, tem o mundo como seu horizonte, como seu na-direção-de-quê (Woraufhin). Na medida em que o Dasein mesmo, por sua vez, é o transcendente, o transcendendo ou a ultrapassagem em sua acontecência própria, o comportamento humano se faz possível. De tal modo que com o título ser-no-mundo, Heidegger não faz senão apreender conceitualmente a estrutura fundamental de sustentação do Dasein, deste ente em cujo ser - transcendência - se dá a possibilidade da descoberta (Entdecktheit) do ente num todo, isto é, com o Dasein abre-se o mundo e, desde o mundo, a possibilidade do comportamento. É porque vige mundo que o Dasein pode retornar ao ente, comportando-se. Mundo é o enigma sempre inserido a priori em cada jogo de ser e comportar-se do Dasein com o ente enquanto ente na totalidade. E não é a outro resultado que Heidegger chegará na sua preleção do semestre de 1929/30, ainda que por caminhos bastante distintos: mundo é a abertura (Offenbarkeit) do ente como tal e no seu todo. E justamente de um tal modo de abertura é que o animal achar-se-ia privado.

\section{A estrutura-como e a formação de mundo}

No que segue, ainda necessitamos esclarecer brevemente o sentido preciso da expressão "abertura do ente como ente na totalidade". Num curso proferido em Marburg no semestre de inverno

que o problema da transcendência na reflexão de Heidegger não se deixa compreender no sentido tradicional, ou seja, ora sob os termos de uma relação entre sujeito e objeto, ora como relação entre o ente humano contingente e o deus incondicionado. Com o conceito de Dasein, Heidegger implode as noções de imanência do sujeito e de contingência do ente criado e, conseqüentemente, o problema da transcendência passa a ser situado num terreno mais originário que aqueles por onde transitam a gnosiologia e a teologia. Para Heidegger, "transcendência é a ultrapassagem que possibilita algo como a existência em geral" (Heidegger, M. Vom Wesen des Grundes. In: _. A essência do fundamento, 1988, p. 35), a tal ponto que ela diz da própria constituição básica e essencial do Dasein, não se referindo nunca a alguma modalidade comportamental do sujeito ensimesmado. 
de 1925/26, intitulado Lógica, a pergunta pela verdade, Heidegger já afirmava: "a estrutura do 'como algo' é, portanto, a estrutura hermenêutica fundamental do ente que denominamos existência (vida humana)". ${ }^{14} \mathrm{Ou}$, de outro modo: "o 'como algo' é a estrutura que corresponde à compreensão enquanto tal, à compreensão que necessita aqui ser entendida como um modo fundamental do ser de nossa existência". ${ }^{15}$ Estes extratos iluminam o que diz Heidegger em Ser e tempo, ao afirmar: "o 'como' constitui a estrutura de expressividade de um compreendido; o 'como' constitui a interpretação [Auslegung]". ${ }^{16}$ Como já fizemos notar, é este como justamente o que permanece recusado ao animal. Para Heidegger, o como firma o seu lugar como uma estrutura formal que se mantém circunscrita ao Dasein do homem, como um momento estrutural de sua própria abertura (Offenbarkeit), como ele se expressaria em 1929/30.

Não temos condições de percorrer aqui as exposições de Heidegger sobre o problema do como, da estrutura-como, empreendidas, em ambas as preleções citadas, por meio de uma discussão do conceito de logos ou, mais especificamente, da sua condição de possibilidade. Entretanto, é necessário ter claro que sua obstinação por alcançar a dimensão originária do como tem em vista o empreendimento de uma discussão de princípio com a tradição da lógica e com a metafísica que a fundamenta, e justamente porque de tal discussão dependeria não só o destino da metafísica, mas, sobretudo, o destino do próprio homem. ${ }^{17}$ É sobre tais bases que se justifica, por exemplo, toda a tematização heideggeriana do problema da proposição enunciativa. Aqui, na medida em que aquilo que se intenta é contribuir com a clarificação da posição de Heidegger sobre o problema da diferença entre o animal e o homem, precisa-

14. Heidegger, M. Logik: Die Frage nach der Wahrheit. In: Gesamtausgabe. Band 21. Frankfurt-am-Main: Vittorio Klostermann, Zweite Auflage, 1995, p. 150 , nota 6 .

15. Idem, ibidem.

16. Cf. Heidegger, M., Sein und Zeit, p. 149.

17. Cf. Heidegger, M. Die Grundbegriffe der Metaphysik: Welt - Endlichkeit Einsamkeit.In: . Gesamtausgabe. Band 29/30, p. 468. 
mos nos restringir ao tratamento da seguinte questão: o que significa comportar-se face ao ente como tal? E falar disso já é falar a respeito de algo que o animal, segundo Heidegger, essencialmente não pode.

Já no curso de 1925/26, Heidegger apresentava sua tematização da originariedade (Ursprünglichkeit) do como-hermenêutico (hermeneutisches Als) face ao como-apofântico (apophantisches Als), o como que se desvenda no juízo, na proposição. Esta discussão seria decisiva em Ser e tempo. ${ }^{18}$ A tese de Heidegger pode ser sintetizada nos seguintes termos: todo encontro do Dasein humano com o ente se dá por meio de um comportamento ocupacional, e a estrutura-como descreve a determinação e configuração das bases desde as quais tal comportamento se faz possível. Heidegger diz:

O nosso ser orientado às coisas e aos homens se move nesta estrutura: algo como algo - resumindo: tem a estrutura do como. Tal estrutura-como não é, por isso, recebida da predicação. Em cada ter-de-haver-se-com [Zu-tun-haben] algo, não estou realizando nenhum enunciado tematicamente predicativo sobre esse algo. Donde a necessidade de insistir expressamente no caráter antepredicativo da estrutura-como. [...] A predicação tem a estruracomo, mas somente de uma maneira derivada. ${ }^{19}$

Há que se precaver aqui de uma compreensão do comportamento ocupacional sob os termos de um produzir (Herstellen). Na chave da práxis fundamental pensada em Ser e tempo, o comportamento ocupacional diz sempre de um deixar-ser (Seinlassen) o ente, e isso de modo casual, segundo o que se dá neste ou naquele momento, num jogo muito parecido com o brincar das crianças. ${ }^{20}$ Comportar-se é, assim, empreender um jogo exploratório das possibilidades, daquilo que é possibilitado pela significância do mundo. Todo comportar-se e ser do Dasein face ao ente como ente

18. Cf. Heidegger, M. Sein und Zeit, § 32.

19. Heidegger, M. Logik: Die Frage nach der Wahrheit. In: Gesamtausgabe. Band 21, p. 144.

20. Cf. Loparic, Z. Ética e finitude. 2a edição revista e ampliada. São Paulo: Editora Escuta, 2004. 
caracteriza-se sempre, deste modo, como uma simples possibilidade de ser. Mundo, assim, não é senão o horizonte de possibilidades do Dasein ${ }^{21}$, e o como (Als), por sua vez, explicita não somente o modo característico a partir do qual o ente pode vir ao encontro do Dasein - irromper na cena do mundo, fazer-se intramundano (innerweltlich) -, mas, sobretudo, a estrutura possibilitadora do encontro, o mundo mesmo.

Para o Dasein, o ente é sempre um já-interpretado, e isso quer dizer, interpretado na sua possibilidade. O que faz do ente um ente intramundano é justamente o seu já-ser-interpretado pelo Dasein, o fato de ele não ser nunca "um puro dado encerrado sobre si”. ${ }^{22} \mathrm{O}$ ente vem à presença por meio da estrutura-como, e esta o articula de tal ou tal modo, sempre segundo um como. A este poder (können) de articulação, Heidegger chamou sentido (Sinn). Sentido, por sua vez, é sempre sentido de ser do ente, entendendose por isso o âmbito da articulação ontológica das possibilidades ônticas no ente. $\mathrm{O}$ ente sempre vem ao encontro do Dasein como um já-intepretado, e interpretado por meio de seu sentido de ser.

Heidegger descreveu o modo de ser do animal como um estar-aprisionado no ambiente onde ele desempenha suas aptidões. Para o animal, tal ambiente, como vimos, é o círculo de desinibições. Na medida em que a própria vida é descrita sob os termos de uma luta ou de um esforço para a manutenção do círculo, ela se distingue essencialmente da abertura característica do homem, a formação de mundo. Num desdobrar-se pulsional peculiar, todo o interagir (Benebmen) animal com seu mundo ambiente se acha marcado por uma essencial dependência com relação ao elemento desinibidor, donde seu estar-aprisionado (Genommenheit). Não chega a irromper no animal - o atesta o seu modo de ser - uma abertura para o ente no seu como, capaz de possibilitar-lhe uma apropriação interpretativa do ente, na chave de um sentido projetado. Para o homem, como Dasein, o ente que vem ao encontro

21. Cf. Paisana, J. Fenomenologia e hermenêutica: a relação entre as filosofias de Husserl e Heidegger. Lisboa: Editorial Presença, 1992, p. 130.

22. Idem,p. 131. 
é já sempre inserido criativamente na trama significativa que se faz e deixa tecer ali onde vigora uma dimensão de sentido, ali onde se dá testemunho do ultrapassamento do ente, da transcendência. Ainda que, dada a herança, nem tudo seja factível ao homem, permanece-lhe aberta, de modo essencial, a possibilidade do novo.

\section{Peter Sloterdijk e a história natural da clareira do ser}

A posição de Heidegger sobre a diferença entre o animal e o homem constitui motivo de indignação para Peter Sloterdijk, autor do opúsculo Regras para o parque bumano: uma resposta à carta de Heidegger sobre o bumanismo. ${ }^{23}$ Para Sloterdijk, a enunciação, por parte de Heidegger, de uma diferença radical entre o modo

23. Acurado diagnóstico dos dilemas que assolam o homem contemporâneo ante o avanço das técnicas de intervenção artificial na matéria viva, o livreto Regras para o parque humano, de Peter Sloterdijk, muito mais a ata de um pronunciamento público do que propriamente um ensaio filosófico, permanece incompreendido. Os próprios círculos filosóficos o têm ignorado resolutamente. Os motivos para isso são os mais diversos, mas ao menos dois se fazem dignos de menção: 1) o caráter aparentemente panfletário do texto, aliado à periculosidade da matéria em pauta, a saber, o colapso do humanismo como mídia domesticadora e humanizadora e a subseqüente necessidade - dada a inevitabilidade da manipulação do material genético dos humanos e da assunção definitiva por parte do homem do controle dos mecanismos de seleção que determinam os rumos da espécie - de se pensar regras para o parque humano; 2) o teor das interpretações filosóficas ali empreendidas, e muito especialmente a interpretação de Heidegger, filosófico a quem o texto de Sloterdijk é endereçado sob a forma de uma carta-resposta, como se lê no subtítulo de seu livro: "Uma resposta à carta de Heidegger sobre o humanismo". Vale observar também que o texto em questão serviu de ponto de partida para um acirrado debate público entre Sloterdijk e Habermas, o qual teve lugar especialmente na mídia impressa alemã durante os meses de setembro e outubro de 1999. Marques analisa os pormenores da recepção do texto de Sloterdijk na Alemanha, fazendo observar que "mais do que às conseqüências éticas da aplicação da genética à seleção e determinação das características da espécie, a polêmica se relaciona a um movimento mais profundo de distensão das férreas diretrizes político-intelectuais que governam, desde o pós-guerra, a interpretação da história alemã recente”. Marques, J. O. "Sobre as Regras para o parque humano de Peter Sloterdijk". Natureza Humana. Revista Internacional de Filosofia e Práticas Psicoterápicas, São Paulo, 4 (2), 2002, p. 363. 
de ser do animal e do homem não passa de confirmação do seu "pathos antivitalístico" e "antibiológico", única explicação possível para o tom "quase histérico" do seu posicionamento. ${ }^{24}$ Partindo de uma interpretação de trechos difíceis e realmente pouco elucidados da Carta sobre o bumanismo, Sloterdijk apresenta ao leitor um Heidegger hiper-humanista, um filósofo "cripto-católico" e de "temperamento provinciano", um homem incapaz de perceber e admitir a tangibilidade - e as evidências de tangibilidade - da "saída dos seres humanos para a clareira". ${ }^{25}$

Faz-se necessário compreender aqui o contexto teórico-filosófico em que se gesta a crítica de Sloterdijk a Heidegger, a saber, sua declarada intenção de empreender uma caracterização da clareira extática no homem - o aí (Da) da compreensão de ser - por meio de um recurso à história natural. Para Sloterdijk, há de se contar a "história natural da clareira", há de se reconstruir os mecanismos por meio dos quais se fez possível, na história da espécie humana, o ficar dentro (Hineinstehen) ou estar-preso-dentro (Hineingehaltensein) do ser humano na clareira. Sloterdijk propõe uma "história real da clareira", como ponto de partida de "qualquer reflexão aprofundada sobre o ser do homem que pretenda ir além do humanismo" (Sloterdijk, 2000, p. 33). Uma história natural da clareira, assim, como reflexão aprofundada sobre o ser humano ${ }^{26}$. Naturalmente, há motivos pontuais pelos quais Sloterdijk julga imprescindível reconstruir a história natural da clareira do ser. Para ele,

O ficar-dentro ou estar-preso-dentro do ser humano na clareira do ser não é de nenhuma maneira uma relação ontológica primitiva,

24. Sloterdijk, P. Regras para o parque humano: uma resposta à carta de Heidegger sobre o bumanismo, p. 25.

25. Idem, p. 33.

26. Em entrevista concedida à Folha de São Paulo, publicada em 10 de outubro de 1999, ele chegou a afirmar: "A questão 'o que é o homem?' coloca-se agora com uma seriedade nunca antes vista na história da humanidade. Por isso, mais uma vez chegou a hora da filosofia: só ela é capaz de refletir na profundidade certa o alcance de uma questão como esta”. Sloterdijk, P. apud Pondé, L. F. Zoopolitica. Peter Sloterdijk defende um código de planejamento biogenético do homem. Folha de São Paulo, São Paulo, 15 out. 1999. 
insuscetível de qualquer exame posterior. Existe uma história - resolutamente ignorada por Heidegger - da saída dos seres humanos para a clareira: uma história social da tangibilidade do ser humano pela questão do ser e uma movimentação histórica no escancaramento da diferença ontológica. ${ }^{27}$

Uma reconstrução detalhada das linhas mestras pré-delineadas por Sloterdijk com vistas ao cumprimento da narrativa histórico-natural da clareira do ser excede os limites do presente trabalho. Aqui, basta dizer que a história natural da clareira consiste em duas narrativas maiores. À primeira delas, uma história natural da "aventura da hominização", também denominada "história natural da serenidade", caberia a tarefa de explicitar os mecanismos da chamada "revolução antropogenética", o processo que, partindo de uma ruptura com o nascimento, em sentido estritamente biológico, leva a espécie humana ao ato de vir-ao-mundo, à entrada na clareira compreensiva do ser. A esta narrativa dever-se-ia associar ainda uma segunda, a história da domesticação humana, do ingresso humano no modo de vida sedentário e da subseqüente construção de casas e cidades, solo político das decisões quanto aos rumos da espécie. Ambas as narrativas convegem num direcionamento ou meta comuns, a saber, "a explicação de como o animal sapiens se tornou o homem sapiens". ${ }^{28}$

O projeto de Sloterdijk, caracterizado aqui em suas linhas gerais, merece atenção. A reconstrução da clareira do ser por meio de um recurso à história natural, de fato, talvez seja exigência que se imponha nos dias de hoje, face aos desafios peculiares de nossos tempos, tais como a manipulação da matéria viva, a realidade da produção da vida em laboratório, situação que faz colapsar paradigmas interpretativos seculares, tais como a tradicional distinção entre natureza e cultura, por exemplo. Entretanto, cabe perguntar criticamente: como é possivel mobilizar um questionamento sobre o homem, por meio de uma reconsideração do papel da natureza

27. Sloterdijk, P. Regras para o parque humano: uma resposta à carta de Heidegger sobre o humanismo, p. 32.

28. Idem, p. 33. 
em sua história, sem incorrer em nenhum reducionismo do tipo naturalista? Aqui, esbarramos em questões bastante delicadas, difíceis. Não só porque acabamos por nos defrontar com o problema de uma relação possível entre discurso filosófico e fazer científico, mas sobretudo porque nos vemos confrontados com dilemas que, como notou Stein, já incomodavam a Kant em sua Antropologia do ponto de vista pragmático, tais como a questão referente à possibilidade ou impossibilidade da admissão de uma simbiose entre uma antropologia filosófica e uma fisiologia..$^{29}$

Como se não bastasse essa dificuldade, há de se notar que o homem de Sloterdijk é, por assim dizer, um homem heideggeriano. Ou não é curioso que Sloterdijk, ao formular suas críticas, fale justamente de uma clareira (Lichtung), preservando o conceito cunhado por Heidegger, já em Ser e tempo, para designar a irrupção ou abertura, no ente, da brecha compreensiva, a transcendência? Ora, é forçoso reconhecer que nas Regras para o parque bumano Sloterdijk já pressupõe - ao propor a reconstrução da história natural da clareira do ser e ao compreendê-la como o caminho adequado de qualquer reflexão profunda sobre o que seja o homem - que o ser-homem do homem determina-se por seu ser-no-mundo, ou por seu estar-na-clareira. Já no decurso de seu esforço narrativoreconstrutivo da história do homem, Sloterdijk diz: "o homem é o produto de um hiper-nascimento que faz do lactente (Säugling) um habitante do mundo (Weltling)".$^{30} \mathrm{E}$ o seu esclarecimento do que seja a linguagem, por sua vez, acentua que tal estar-no-mundo é um êxtase (Ekstase): "as linguagens tradicionais do gênero humano tornaram capaz de ser vivido o êxtase do estar-no-mundo, ao mostrar aos homens como esse estar no mundo pode ser ao mesmo tempo experimentado como estar-consigo-mesmo". ${ }^{31}$

29. Cf. Stein, E. Exercícios de fenomenologia: limites de um paradigma. Ijuí: Editora Unijuí, 2004, p.178.

30. Sloterdijk, P. Regras para o parque humano: uma resposta à carta de Heidegger sobre o bumanismo, p. 34 .

31. Idem, p. 35. 
Estas nos parecem indicações suficientes de que também Sloterdijk admite uma diferença essencial entre o animal e o homem. A inquietação que movimenta a argumentação aqui empreendida é, contudo, justamente a seguinte: ainda que Sloterdijk defina o homem como "a criatura que fracassou em seu ser-animal (Tiersein) e em seu permanecer-animal (Tierbleiben)" ${ }^{\prime 2}$, ele deixa em segundo plano qualquer consideração ontológica mais detalhada sobre o modo de ser da própria animalidade, bem como não investe numa tematização da diferença enquanto tal, justamente o que faz Heidegger, por exemplo, em sua preleção de 1929/30 (cf. seção 2). Além disso, Sloterdijk parece resolutamente ignorar o sentido da distinção operada por Heidegger entre os domínios ontico e ontológico de averiguação. Para Heidegger - Sloterdijk tem razão - a diferença entre o animal e o homem é mesmo uma diferença ontológica. ${ }^{33} \mathrm{O}$ que ele não observa, e aqui situamos mais pontualmente nossa avaliação crítica, é que uma diferenciação de cunho ontológico, em Heidegger, não diz respeito a distinções de configuração ôntica, de propriedades qüididativas (materiais, físico-químicas, cognitivas, anímico-espirituais, etc), mas restringese tão-somente às especificidades dos modos de ser, refere-se a uma diferenciação modal, e somente isso. ${ }^{34}$

Dito de outra maneira: as acusações de Sloterdijk a Heidegger, segundo as quais um pathos antivitalista e antibiológico operaria na proposição, por parte deste último, de uma diferença radical entre o animal e o homem, não levam em conta, com a abrangência necessária, a peculiaridade do discurso ontológico de Heidegger, essencialmente voltado à apreensão do modo de ser dos entes. Por essa razão, argumentamos que a despeito da relevância do projeto de Sloterdijk - cuja exeqüibilidade e proficuidade caberá ao tempo julgar propriamente - suas considerações tendem a simplificar

32. Idem, p. 34 .

33. Idem, p. 25.

34. Cf. Beelmann, A. Heideggers hermeneutischer Lebensbegriff. Eine Analyse seiner Vorlesung "Die Grundbegriffe der Metaphysik. Welt - Endlichkeit Einsamnkeit”. Würzburg: Königshausen \& Neumann, 1994, p. 15. 
o complexo horizonte de problemas por onde Heidegger transita ao enunciar uma diferença radical entre o animal e o homem e ao propor-se a e enfrentá-la filosoficamente. Para Heidegger, qualquer investigação acerca do fundamento da compreensão de ser e da condição de possibilidade do comportamento humano é de cunho essencialmente ontológico. No decurso de um questionamento desta natureza, trata-se de apreender e fixar conceitualmente o modo de ser de um ente cujo ser se caracteriza por uma diferença peculiaríssima, a saber, o caráter de formação de mundo (Weltbildend), marca de sua radical finitude. Uma arbitrariedade de Heidegger? De modo algum.

Para o autor de Ser e tempo, o que está em jogo na defesa do discurso ontológico é o asseguramento das condições filosóficas não-metafísicas para o empreeendimento de uma investigação condizente com o modo de ser do Dasein, segundo método próprio. Pois, conforme expusemos anteriormente (cf. seção 3), a transcendência da existência, a partir da qual o homem pode existir como ser-no-mundo e como formador de mundo, descreve um âmbito ou território peculiaríssimo, inacessível ao método objetificante da ciência moderna e absolutamente distinto daquele em que se dá o desdobramento da perturbação animal, o círculo de desinibição. $\mathrm{O}$ onde do desdobramento fático de um existir humano chama-se mundo e constitui-se como um horizonte de sentido compartilhado, possível na base da estrutura-como, a estrutura básica da compreensão de ser (cf. seção 4). Assim existindo, o homem é um projeto-lançado, sempre e essencialmente finito, carente de explicações e fundamentações últimas. $\mathrm{O}$ que difere o homem do animal, e para isto não atenta Sloterdijk em seu texto, é um peculiar tipo de ter-de-ser (Zu-Sein) que já sempre o mobilizou num exercício de formação de mundo. Todo o ente que vem ao seu encontro é já interpretado na dinâmica própria da estrutura de sentido que é o mundo, o aí $(D a)$ onde o homem se compreende, onde ele é o que é. E este âmbito do existir fático dos humanos não se deixa compreender - é esta, em suma, a posição de Heidegger - senão por meio de um discurso filosófico, fenomenológico-hermenêutico. 


\section{Bibliografia}

BEELMANN, A. Heideggers hermeneutischer Lebensbegriff. Eine Analyse seiner Vorlesung "Die Grundbegriffe der Metaphysik. Welt - Endlichkeit - Einsamnkeit”. Würzburg: Königshausen \& Neumann, 1994.

HEIDEGGER, M. Vom Wesen des Grundes. In: A essência do fundamento. Edição bilíngüe. Lisboa: Edições 70, 1988. . Metaphysiche Anfangsgründe der Logik im Ausgang von Leibniz. In: . Gesamtausgabe. Band 26. 2., durchgesehene Auflage. Frankfurt-am-Main: Vittorio Klostermann, 1990. . Die Grundbegriffe der Metaphysik: Welt - Endlichkeit-Einsamkeit. In:__. Gesamtausgabe. Band 29/30. Frankfurt-am-Main:Vittorio Klostermann, Zweite Auflage, 1992.

Logik: Die Frage nach der Wabrbeit. In: Gesamtausgabe. Band 21. Frankfurt-am-Main: Vittorio Klostermann, Zweite Auflage, 1995.

. Sein und Zeit. Achtzehnte Auflage. Tübingen: Max Niemeyer Verlag, 2001.

LOPARIC, Z. Ética e finitude. $2^{\text {a }}$ edição revista e ampliada. São Paulo: Editora Escuta, 2004.

MARQUES, J. O. "Sobre as Regras para o parque humano de Peter Sloterdijk". Natureza Humana. Revista Internacional de Filosofia e Práticas Psicoterápicas, São Paulo, 4 (2), 2002,363-381. Disponível em $<$ http://www.unicamp.br/ jmarques/pesq/Sobre_as_regras_para_ o_parque_humano.pdf >. Acesso em: 10 out. 2009.

PAISANA, J. Fenomenologia e hermenêtitica: a relação entre as filosofias de Husserl e Heidegger. Lisboa: Editorial Presença, 1992.

PONDÉ, L. F. Zoopolítica. Peter Sloterdijk defende um código de planejamento biogenético do homem. Folha de São Paulo, São Paulo, 15 out. 1999.Disponívelem <http://www1.folha.uol.com.br/fsp/mais/fs101 0199905.htm >. Acesso em: 28 ago. 2009.

SLOTERDIJK, P. Regras para o parque humano: uma resposta à carta de Heidegger sobre o humanismo. Trad. de José Oscar de Almeida Marques. São Paulo: Estação Liberdade, 2000.

STEIN, E. Exercícios de fenomenologia: limites de um paradigma. Ijuí: Editora Unijuí, 2004. 